Article

\title{
A Preparation for Reuse Trial of Washing Machines in Ireland
}

\author{
Michael Johnson *, Kathleen McMahon and Colin Fitzpatrick
}

Department of Electronic and Computer Engineering, University of Limerick, V94 T9PX Limerick, Ireland; Kathleen.mcmahon@ul.ie (K.M.); Colin.Fitzpatrick@ul.ie (C.F.)

* Correspondence: michael.johnson@ul.ie; Tel.: +353-61-202700

Received: 23 October 2019; Accepted: 14 January 2020; Published: 6 February 2020

\begin{abstract}
This paper presents the results of a "preparation for reuse" trial of washing machines in Ireland. For the trial, a methodology for the quantitative assessment of potentially reusable appliances in the waste electric and electronic equipment (WEEE) stream is developed and applied to a statistically significant sample allowing the study to quantify a theoretical potential for the "preparation for reuse" of washing machines in the WEEE stream in Ireland under current collection conditions. For a statistically significant sample size, data on preparation for re-use trials conducted on B2C (Business-to-Consumer) WEEE was collected and reviewed. From the 23,129 appliances which were accepted into the trial, the study found that 327 of these washing machines were successfully prepared for reuse and sold back into the Irish market, leading to an overall reuse rate of $1.5 \%$. A quantitative analysis of the trial data is presented with a complimentary qualitative evaluation which provides insights into the causes for this low reuse figure, the occurrence of specific repairs and recommended actions to address these.
\end{abstract}

Keywords: product design; preparation for re-use; waste electric and electronic equipment; large household appliances; repair; Ireland

\section{Introduction}

The increase in demand for consumer electronics is having a corresponding increase on the global demand for finite raw materials. This increase in discarded electrical and electronic equipment (EEE) due to the linear economy model prevalent in modern society is creating a growing waste problem. Factors such as the latest fashion trends, styles and public perception are all contributing factors to this problem, with increasing difficulties encountered in maintaining or repairing such products. Advancements in technology and growing prosperity have meant that the consumption of EEE has experienced an unprecedented growth at a global level in recent years, resulting in negative side effects such as resource depletion and environmental pollution. EEE re-use and preparation for re-use is seen as one potential/progressive response to this shortening of product lifetimes [1-4]. Re-use and preparation for re-use attempt to optimise the "use" phase of a product for greater resource efficiency, and is one method of addressing this unprecedented pressure on resources and manufacturing burdens through the extension of product lifetimes via reuse and refurbishment.

To help achieve this in Europe, the European Union (EU) has introduced the waste hierarchy as part of the waste framework directive, citing waste prevention (direct re-use) as the ideal waste management strategy, with preparation for re-use as the second preferred option for waste electric and electronic equipment (WEEE), followed by recycling, recovery and disposal as subsequent tiers in the hierarchy. Of all WEEE handling strategies, preparation for re-use is the most desirable option, as it ensures that maximum product potential is recovered while utilising the minimum amount of resources. Preparation for reuse focuses on the recovery of end-of-life products in the WEEE stream, 
enabling them to be reused and recirculated in the market for longer product lifetimes and extended product use-phases.

Within the EU, the revised EU Waste Framework Directive 2018/851 [5] is the overarching piece of legislation across the European Union which covers all waste management in the EU. This revised Directive (EU) 2018/851, amending Directive 2008/98/EC, includes a series of new measures, including new obligations to measure and eventually set targets for all types of re-use within the EU. However, the current state of knowledge and practice of WEEE (preparation for) re-use in Europe is still fragmented and usually difficult to translate across national borders. With only a few notable exceptions, preparation for re-use of WEEE across Europe is very low. One of the leading examples of re-use and preparation for re-use in Europe is in the Flemish region of Belgium. Here, a specific set of policy measures has enabled re-use to grow consistently over the past 10 years and re-use figures now stand at $4.52 \mathrm{~kg} / \mathrm{capita}$, employing 5045 people and serving over 4.6 million clients [6]. France is also placing an emphasis on re-use in its WEEE management systems and has established a national partnership for re-use with the social economy, which now employs 2300 people and sees $2 \%$ of WEEE collected being prepared for re-use, with LHAs (Large Household Appliance) dominating these figures [7].

In Ireland, The Irish Waste Management Policy [8], published in July 2012, outlines the roadmap for Ireland's progression from a landfill-oriented waste management system towards a more circular economy model, where waste reduction and resource recovery are realised through the application of appropriate technologies and procedures. These include prevention and minimisation, re-use, recycling, recovery and disposal, as predicated by the EU waste hierarchy. The Waste Framework Directive is transposed at a national level through the "European Communities (Waste Directive) Regulations 2011 (Statutory Instrument No. 126 of 2011)" [9], as amended by the "European Communities (Waste Directive) (No. 2) Regulations 2011 (Statutory Instrument No. 323 of 2011)" [10]. As is acknowledged within the Irish questionnaire return on the implementation of Directive 2008/98/EC [11], much of the provisions of the 2008 WFD were already enshrined in national primary legislation by the 1996 Waste Management Act and associated Regulations made thereunder.

Addressing the need for measuring and eventually setting targets for all types of re-use in the EU, the quantitative empirical case study described in this article assesses the potential of the washing machines returned in the Irish WEEE stream for preparation for reuse based on primary data acquired across 23,129 machines collected and examined in Dublin, Ireland.

The remainder of this paper is organised as follows. Section 2 presents a relevant literature review, considering features of re-use and preparation for re-use within the academic literature. Section 3 presents the methodology developed for the quantitative assessment of these potentially reusable appliances in the WEEE stream. This assessment method is then applied to the empirically gathered primary data and the results presented in Section 4. Finally, Section 5 of this paper presents the conclusions and recommendations of this research, presenting the findings as they apply to re-use and preparation for re-use for the household appliance category of washing machines and dishwashers.

\section{Literature Review}

Figure 1 shows an overview of the Irish WEEE Producer Responsibility Model for B2C with the compliance schemes. It includes all of the major contributors to the supply chain and associated product life cycle. This does not include any leakages in the WEEE collection chain through informal or non-authorised channels. 


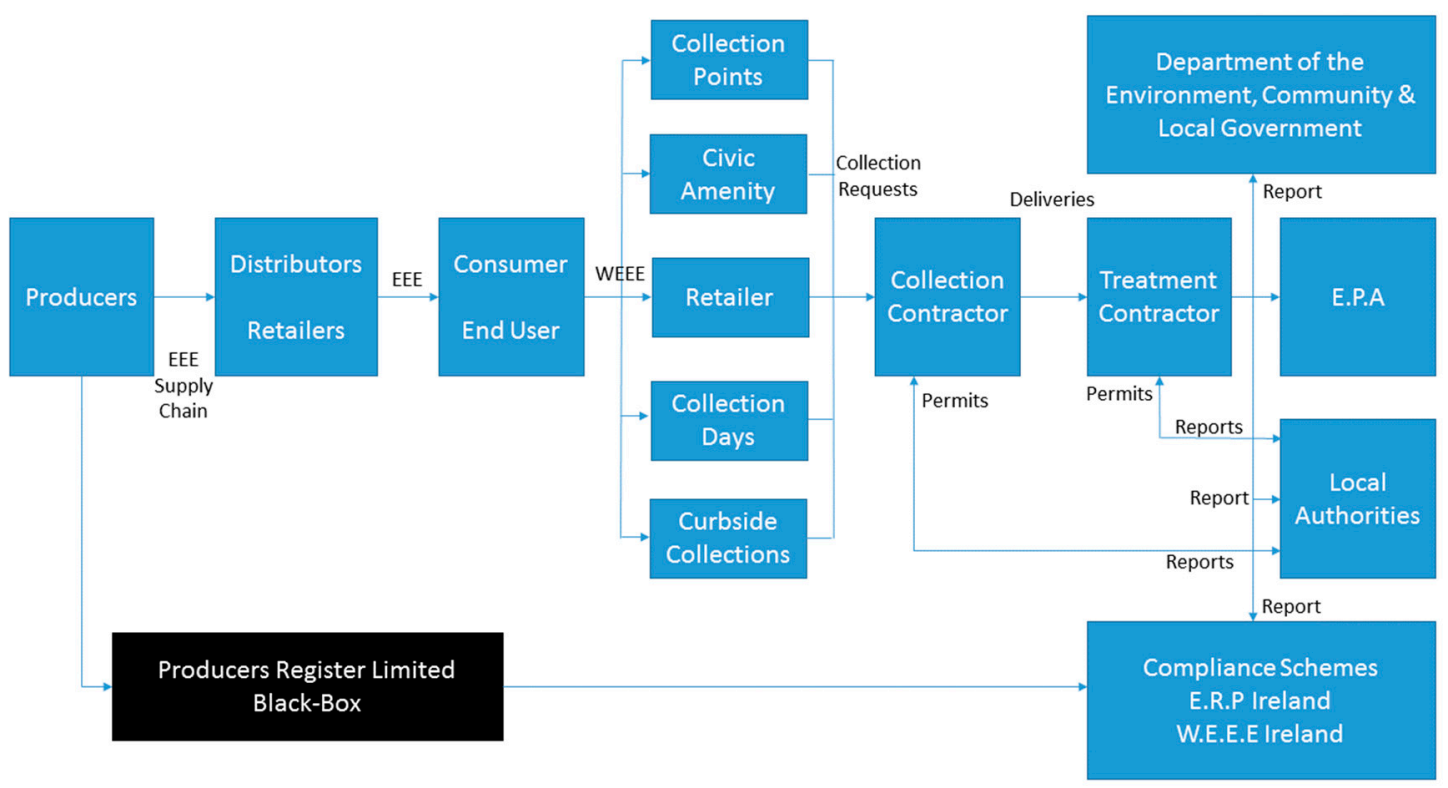

Figure 1. The waste electric and electronic equipment (WEEE) flow model in Ireland.

Under the WEEE directive, the Compliance Schemes are producer responsibility schemes operated by a producer responsibility organisation (PRO). The PRO (or in legislative parlance approved body) is a non-profit organisation that takes on the obligations of its producer members for the collection, treatment and ESM of WEEE.

There are two approved PROs in the WEEE area in Ireland; WEEE Ireland and the European Recycling Platform (ERP Ireland). These PROs are approved by the Minister for Energy, Climate Action and the Environment and operate subject to such conditions of approval as the Minister sees fit. B2C producers of EEE can join either of these PROs or self-comply with the WEEE Regulations/Legislation. At present in Ireland, no B2C producers avail of this latter option, resulting in all compliant producers being a member of either WEEE Ireland or ERP Ireland. B2B producers of EEE do not have the option to join a PRO so have to self-comply and report to the Environmental Protection Agency (EPA).

Preparation for re-use occurs after items of EEE become WEEE. According to the Waste Framework Directive, Article 3.16, "preparing for re-use" means "checking, cleaning or repairing recovery operations, by which products or components of products that have become waste are prepared so that they can be re-used without any other pre-processing". Preparation for re-use occurs once the product has entered the waste stream (as shown in Figure 2) and, as such, is a waste activity. Preparation for re-use therefore requires a company/individual to obtain all of the appropriate authorisations, permits, etc. for waste activities. 


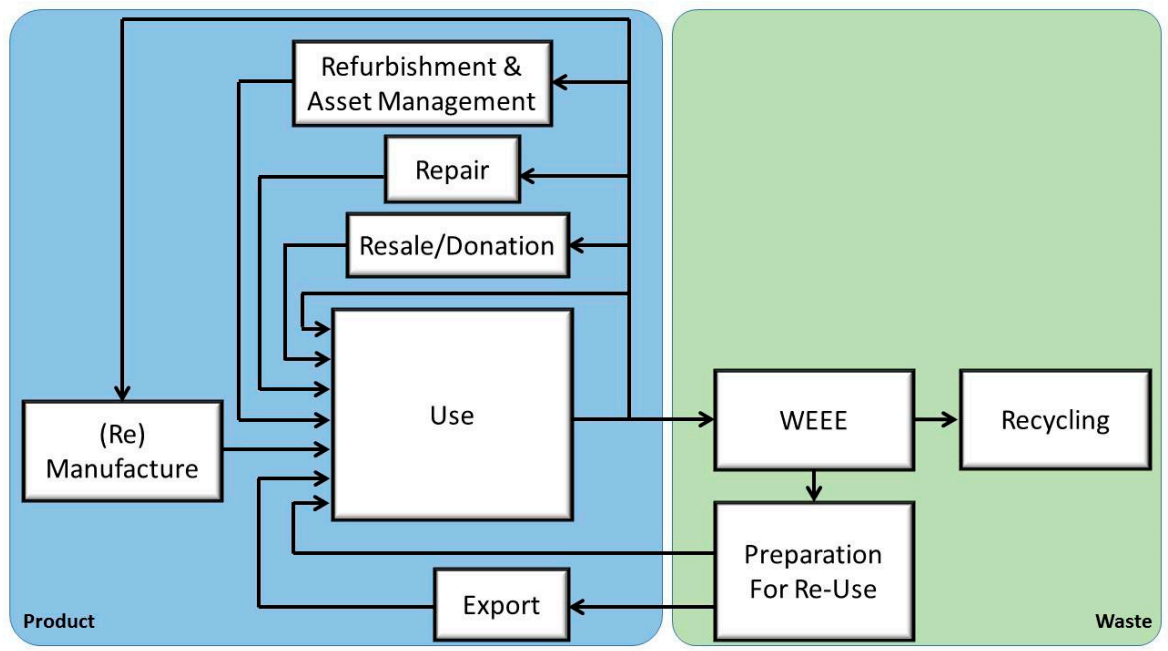

Figure 2. Preparation for reuse in the WEEE flow.

Preparing for re-use may be viewed as a means of diverting waste material from disposal options (e.g., landfill) and is therefore considered preferable to recycling and other recovery methods in the waste hierarchy framework, shown here in Figure 3. EEE that falls under the scope of WEEE and is not regarded as being of sufficiently high quality or standard for preparation for re-use activities will be re-entered into the prior waste stream and treated accordingly under waste legislation. Only when such WEEE, after preparation for re-use, meets the criteria for re-used products can it achieve "end-of-waste" status through being prepared for re-use and be regarded as a (second-hand) product. Re-use should never be considered as a complete solution for WEEE management; instead, products should ultimately feed into efficient recycling systems when their (eventual) use phase is complete [12].

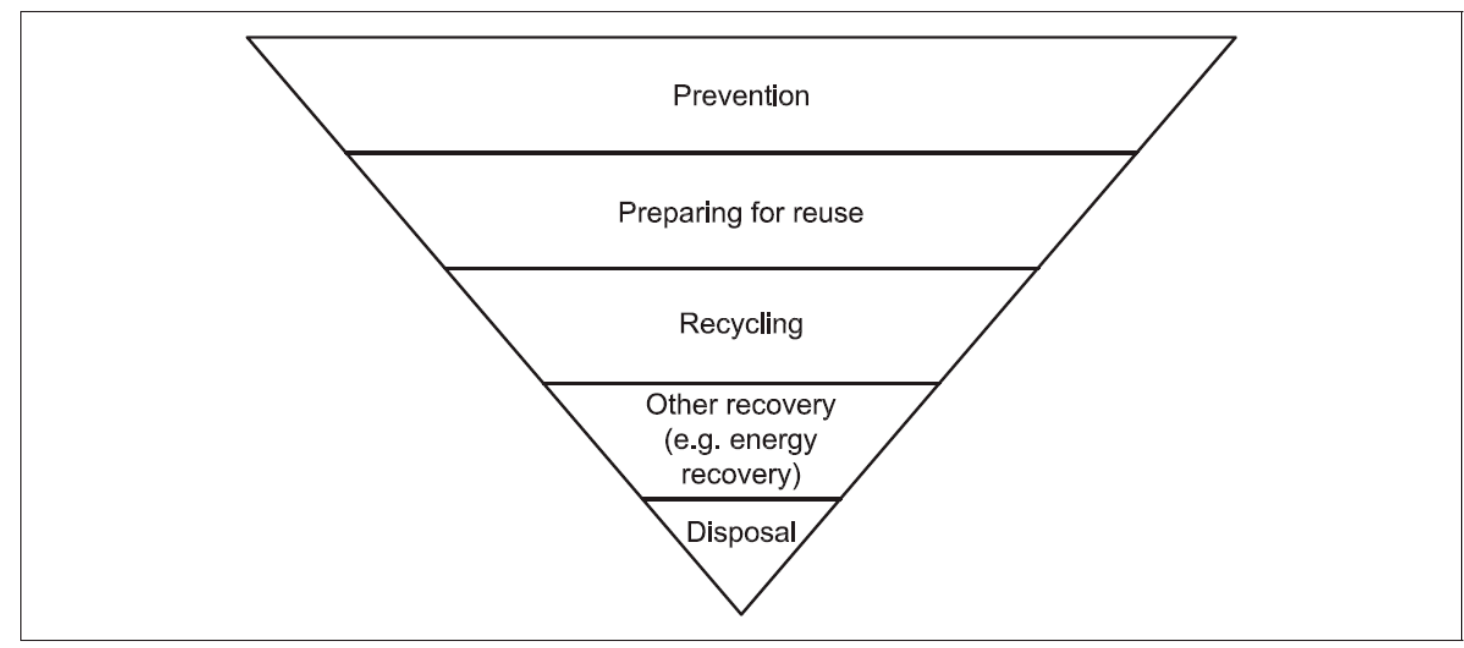

Figure 3. The waste hierarchy [image courtesy of PAS141].

In Ireland, McMahon et al. [13] discuss how re-use and preparation for re-use are currently in sharp focus across the European Union's (EU) emerging legislation on waste management and the circular economy. The authors conducted interviews with stakeholders in the preparation for re-use of WEEE across the United Kingdom, Belgium, France, and Austria, where these systems are considered successful, and in Spain, the first country in the EU to have deemed preparation for re-use targets separate to those for recycling necessary. These are compared and contrasted with similar interviews conducted in the Republic of Ireland, where the preparation for re-use system has not yet developed to a successful level, and factors reported which are facilitating or inhibiting the successful adoption 
of preparation for re-use. Factors for the success of preparation for re-use systems included social enterprise involvement, the use of required quality standards, access to material at the point of end user surrender and facilitating positive relationships between preparation for re-use organizations and the producer representative organizations organizing the waste streams.

Re-use and preparation for re-use have become one of the " 3 Rs" (reduce, re-use, recycle) promoted by environmental agencies such as the US Environmental Protection Agency [14], the UK Waste and Resources Action Programme [15] and is expressed as part of China's circular economy plan [16]. In particular, EEE re-use has been prioritised by a wide range of global policies and regulations as a prudent approach for conserving resources and reducing environmental pollution. The majority of laws that regulate movement and disposal of equipment containing potentially hazardous materials urge re-using used equipment, e.g., the EU WEEE Directive [17], the EU Eco-design Directive [18], the EU Waste Framework Directive [19], China Decree 551 [20] and the Illinois Electronic Products Recycling and Re-use Act [21].

Ongondo et al. [22] have shown that management practices for WEEE vary strongly within different countries. In Europe, the study on preparing for re-use [23] has considered the question of re-use across all of the EU Member States. The main report findings have shown that there are many different forms of management organisations and practices for re-use and preparation for re-use currently in force across the EU. This makes evaluating the potential for re-use in the EU difficult. In general, re-use and preparation for re-use is not well developed at the EU level and, with few exceptions, they are also not well developed at the Member State level. Therefore, the implementation of separate re-use/preparation for re-use targets at a European level faced several difficulties, which have to be addressed before an EU target can be set. Finally, the specification of output-/material-based targets, as opposed to the more traditional percentage figures used thus far, is not recommended yet; this is because of the limited availability of databases for assessing the feasibility of such targets and their limited benefits compared with a further enforcement of selective treatment and increasing collection rates. The report concluded that the new recovery targets to be applied from 2018 onwards are consistent with those introduced previously under the WEEE Directive. The study closes with the reiteration that re-use and preparation for re-use is a desirable, viable and recommended pursuit for the EU Member States.

Within the EU, charitable organisations conduct the major part of processing municipally collected WEEE for preparation for reuse [14,24]. However, the overall quantity of goods undergoing such recovery operations for remarketing is minimal. Messmann et al. [25] identify a strong need for a distinct quota for re-use, since legislation promotes the preparation for reuse as the preferred waste management option compared to recycling, which is contrary to current practice. Relevant research analyzes organizational structures, the legal framework, and generic recommendations for enforcing the second priority of the waste hierarchy on a qualitative basis, targeting WEEE. O'Connell et al. [26] presents a comparative analysis of re-use and non-re-use scenarios from an environmental and economic perspective. Pérez-Belis et al. [27] conducted an in-depth literature review focusing on inter alia management, generation, characterization, and reuse of WEEE, which Queiruga and Queiruga-Dios [28] compliment in their work but state that "further case studies are needed in countries that practice greater reuse".

In the UK, Beasley and Georgeson [29] describe the reuse landscape and derive recommendations for improving in from both and industrial and government viewpoint. Also in the UK, Cole et al. [30] report on some of the barriers to reuse of EEE. Interviews with stakeholders including product designers, manufacturers, users, waste managers, policy makers and academics identified three inter-connected factors limiting opportunities and instances of reuse of EEE, highlighting that both systemic and consumer barriers to increasing levels of reuse exist. Specifically, the three factors found were producer reluctance, unsuitable collection infrastructure and cultural issues. A larger body of work identifies some of the challenges currently hindering preparation for re-use and the present restricted access to reusable goods. Common solutions to these challenges include improvements 
in legislation $[1,22,24,29,31]$, consumer communication and information $[24,29,31,32]$, cross-sector engagement $[24,29,31-36]$ and improvements in the organizational structures on-site.

Estimates on the potential for re-use of WEEE, comparable to the research presented in this body of work, are also presented in the literature. In the UK, the WRAP (Waste and Resources Action Programme (UK)) study [37] found that $44 \%$ (by weight) of WEEE surveyed at UK collection points are viable for reuse. A supplementary visual inspection of the items by a site official resulted in a higher estimation of the reuse potential for WEEE (63\%) being proposed. An earlier survey [36] among 1450 households in England suggests a comparable reuse potential of 49\% for WEEE. Messman et al. [25] have considered the preparation for reuse situation in the German state of Bavaria. The authors assessed waste stream properties and potentials across 61 collection points in Bavaria, analysing the quality, damages and other properties of the returned items and their potential for preparation for re-use. The researchers found that between $13 \%$ and $16 \%$ of the waste streams could immediately be prepared for reuse. A further potential of $13 \%-29 \%$ could be unlocked through changes to the mode of collection, storage and the overall treatment of wastes at Bavaria collection points. Most notably, $86 \%$ of identifiable damage caused to WEEE is attributed to a lack of sufficient weatherproof roofing.

Parajuly and Wenzel [37] have investigated the reuse and recycling market potential of small WEEE and monitors in Denmark based on a number of different criteria. The authors found that such items have a high reuse potential, especially when their re-sale value is considered. Considering the potential revenues from resale as well as from material recovery, it was found that with $22 \%$ and $7 \%$ of fully functional products in the fractions 'small appliances' and 'monitors' respectively, the results suggest resale value of up to $€ 247$ per cage of the collected household WEEE in the study.

In their research, Bovea et al. [38] propose a potential application of the "preparation for reuse" strategy in the context of the European WEEE Directive. The study allows for assessment and estimation of the potential reuse of small WEEE. Domestic appliances such as microwaves, vacuum cleaners, hair dryers, etc. were visually inspected, functionally checked and had safety inspections defined. From these tests, reuse protocols are defined in checklist format. These checklists are ideally suited for reuse enterprises, where there is a distinct shortage of reuse protocols at present. Out of a sample of 96 items considered in the study, $68 \%$ were classified as potentially reusable.

From the study, WEEE is classified as being either fully functional and many be directly reused (items can be used by a second consumer without prior repair operations), requiring refurbishment and/or repair (restoration of products to working order, although with possible loss of quality) or needs to be recycled. The study sampled $87.7 \mathrm{~kg}$ ( 96 units)) of WEEE and found that $30.2 \%$ of the WEEE needed to be recycled, $67.7 \%$ required refurbishment and repair and only $2.1 \%$ of all the WEEE sampled could be directly reused with only minor cleaning.

The wider global literature on re-use and preparation for re-use includes research on various WEEE management strategies in different countries and recycling approaches for specific types of equipment. Some noteworthy examples include an assessment of take-back policies in India [39], an analysis of e-waste decision factors in Mexico [40], the design of an e-waste system in Turkey [41,42] and a Korean policy development review [43].

Re-use and Preparation for Re-use has also featured in circular economy and material production research. In Hertwich et al. [44], the authors consider the impact which re-use can have on greenhouse gas (GHG) emissions and their reduction, Today, approximately $25 \%$ of all energy produced worldwide is used for the production of materials. More efficient use of these materials through re-use and preparation for re-use schemes would present a significant opportunity for the reduction of GHG emissions. Material efficiency (ME) strategies such as light-weighting, downsizing of and lifetime extension for products, reuse and recycling of materials, and appropriate material choice are considered in this research. The emissions savings from such ME strategies is also investigated in more detail, as it remains poorly understood, owing in part to the multitude of material uses and diversity of circumstances and in part to a lack of analytical effort. The authors found that there can be a systematic trade-off between material use in the production of buildings, vehicles, and appliances and energy use 
in their operation, requiring a careful life cycle assessment of ME strategies. Repair and remanufacture of electronic products and appliances can also result in emission reductions, which have been quantified by the authors on a case-by-case basis and are generally difficult to generalise.

The data and results presented in this research compliment these figures by presenting a study on the preparation for re-use potential of white goods/household appliances in Ireland using a structured approach as described in the next section. The data presented in this research may be used as an aid to identify and set preparation for re-use figures by the appropriate organisations and supports the selection of suitable actions in order to improve the preparation for re-use potential of WEEE in the future.

\section{Materials and Methods}

This section considers the methodology and approach used to survey the LHA and specifically white goods such as washing machines and dishwashers for this study. The research methodology adopted for this study followed 5 distinct stages, as shown in Figure 4.

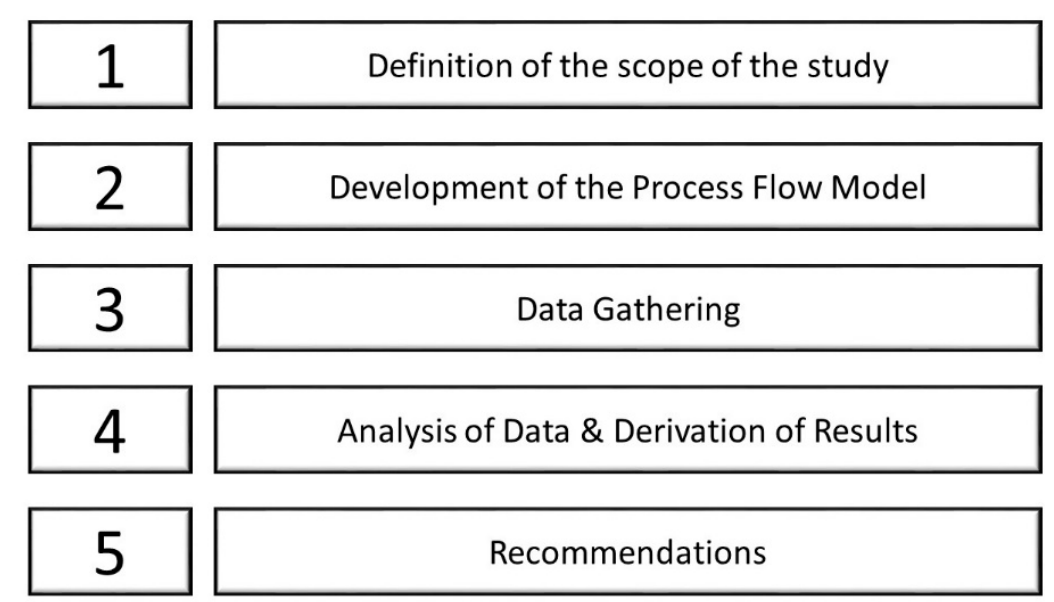

Figure 4. Process flow model used during this study.

In the first step, the research aim is to define the scope of the study by setting out the goal of quantifying the re-use potential for washing machine WEEE in Ireland as the main scope of the research. In the second stage, a process flow model for the study is developed which is then used to evaluate and test all of the WEEE appliances tested during the study. In the third stage, a statistically significant set of primary data is collected from recycling and preparation for re-use studies in order to allow the quantification of such re-use potential. Washing machines were inspected and selected for preparation for re-use trial, with data on numbers of machines inspected, number selected for the trial and numbers of machines passing each stage of the trial process being recorded. Additional information on all repairs and refurbishments needed to the machines were also collected during the data gathering phase of the trial. This empirical approach applied in this quantitative empirical study evolves from expert discussions with the company undertaking the trial. In the fourth phase, this collected data is compiled into a database. From this, information on collected amounts, overall item quality, pass/fail rates for each stage of the process and item-specific reasons for exclusion from the preparation for re-use process are collected and tabulated. In total, 23,129 units of LHA/WEEE were sampled during the course of the 21-week study. Combining this primary gathered and the results of the analysis conducted in step 5 of the process, a theoretical potential for the preparation for reuse figure is quantified for the LHA/white goods WEEE stream, as well as recommendations put forward, identifying the foremost challenges and issues facing the preparation for re-use of such appliances. The report then presents some recommended actions in order to address these issues.

Rehab Recycle, established in 1984, is an Irish-based company responsible for recycling of WEEE, IT equipment and sundry. The primary data gathered for this research survey was conducted by the 
company as part of a LHA WEEE preparation for reuse trial at their site in Dublin, Ireland. The aim of the trial was to determine the viability of preparation for re-use for LHA from the post collection B2C WEEE stream in Ireland. The trial was further concerned with investigating the preparation for re-use process, considering the logistics and implementation issues of such a process and identifying necessary parameters for the successful implementation of such a system on a larger scale in the future. It also affords the opportunity to empirically quantify preparation for re-use potential of WEEE in Ireland.

The trial duration was 21 weeks and took place at a consolidation point for B2C WEEE collections. The project specifically focused on the viability of refurbishing waste washing machines discarded by the end user.

All appliances considered in the trial were collected through standard WEEE reclamation channels such as Civic Amenity Sites and Retailer collections. Trucks containing a mix of LHA for WEEE were used to transport the appliances to the WEEE recycling plant for processing. Upon arrival at the processing plant, machines were inspected using a multi-stage visual and functional assessment process. This was done to evaluate the re-use potential of all washing machines for preparation for re-use. Appliances deemed acceptable were entered into the trial. Figure 5 shows the steps or stages involved in the trial process, with Figure 6 showing the associated process flow model used during the trial.

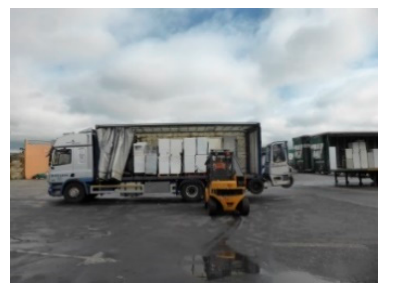

(a)

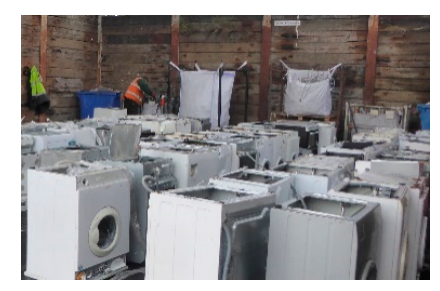

(b)

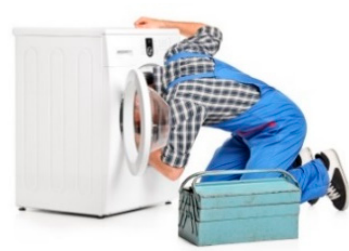

(c)

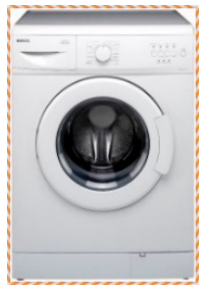

(d)

Figure 5. (a) WEEE is delivered to the collection point; (b) WEEE is visually inspected and appliances with re-use potential selected; (c) LHA is repaired and tested for functionality; (d) refurbished washing machine is available for purchase/sale.

The project specifically focused on the viability of refurbishing white goods/LHA appliances discarded by the end user. Difficulties with refrigerator gas management in cold WEEE (fridges and freezers) excluded these appliances from this trial. Excessive and specialised labour requirements precluded the use of hobs, ovens and cookers from the study. Similarly, no gas power appliances were to be considered for refurbishment.

As shown in Figure 6, the study adopted a 2-tier approach to quantifying the re-use potential of all of the LHA sampled. The first tier is a "Visual Assessment and Functional Assessment" stage, where the quality of the item is the main success factor for the feasibility of re-use. The assigned quality of goods is based on a visual estimation of the overall condition of the item, categorised using a six grade system.

Grade 1 is considered "good as new", Grade 2 items may require some cleaning, Grades 3 and 4 exhibit medium signs of wear and tear, such as heavier scratches, minor damage or noticeable defects. Grade 5 then refers to heavier signs of usage, e.g., broken components that are integral to the product's function, while pieces rated Grade 6 may have lost their structural integrity entirely. For this study, only items which meet the Grade 1 or Grade 2 standard are considered as candidates for preparation for re-use, requiring minimal preparation effort, while all remaining grades are considered unsuitable for re-use. 


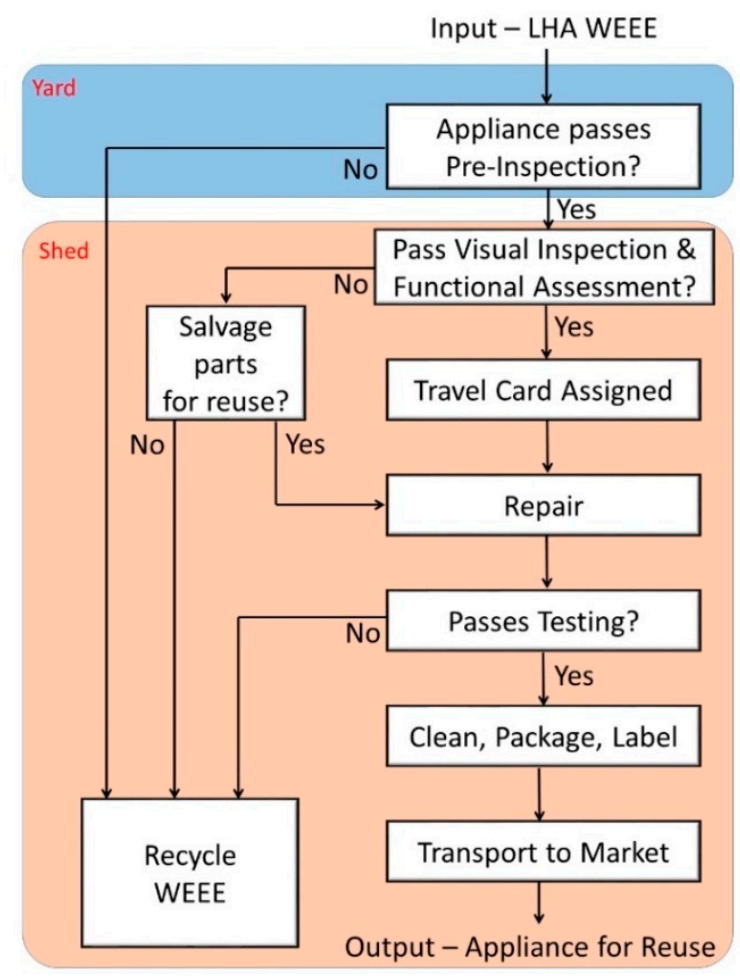

Figure 6. Preparation for re-use trial process flow diagram.

Items in Grades 3-6 which have failed this inspection process are harvested for re-use parts before being re-assigned for recycling. Grade 1 or Grade 2 appliances which pass the first stage are then taken for further examination, repair and refurbishment in order to be successfully prepared for re-use. Items which could not be repaired for whatever reason at this stage are also harvested for re-use parts at this point. Appliances which are successfully repaired and refurbished are then cleaned, labelled and packaged before being sold as refurbished appliances. Data was gathered at all stages for later analysis.

Not all of the WEEE which was collected was deemed fit for re-use. The analysis of the causes of appliances failing the respective stages of the study and the associated damage noted is provided in this report in order to complement the quality assessment section of the study. The most salient information gathered in this respect concerns the identification of when the damage occurred-during the use phase of the item (which normally meant the item needed repair in order to be returned to working order) or after the appliance had become WEEE and was returned, transported or being stored at the collection point, which usually meant the appliance suffered some external or "cosmetic" damage which precluded its inclusion in the second stage of the study, irrespective of functional status.

The next section of this article presents further information on the ratio of goods selected or rejected for re-use, with only a relatively small portion of the LHA WEEE being selected each week during the trial for subsequent re-use testing (in the visual inspection and functional assessment stage).

\section{Results and Discussion}

With the empirical collection of primary data at the Irish collection point completed, the findings were compiled into a database of results. This section presents the results of these findings. The LHA/white goods WEEE stream considered in this study can be aggregated in terms of quantity (Section 4.1), quality (Section 4.2) and the perceived cause of failures (Section 4.3). 


\subsection{Quantities}

During the course of the primary data collection for this study, 23,129 items of WEEE were recorded. This were predominantly white goods appliances such as washing machines and dishwashers. All items were collected at the Rehab Recycle collection point in Ballymount in Dublin, Ireland.

In total, 23,129 LHA/white goods WEEE were inspected during the course of this trial. Of these, 1134 machines (4.9\%) were selected for inspection and functional assessment during the second step of the trial process. From these, 327 washing machines were successfully prepared for re-use, refurbished and sold as re-use appliances during the course of this study, giving an overall re-use rate of $1.5 \%$. Of the remainder, 635 appliances either could not be repaired or failed the testing phase. These appliances were recycled, with the remaining machines from the trial process used for spare parts and parts harvesting operations during the course of the trial.

Over the duration of the 21-week trial, this represented an average of $1.5 \%$ of machines being re-used per week. These 327 washing machines would equate to a figure of 810 washing machines repaired over the course of a year. Of the 1134 machines selected for functional assessment, 535 passed assessment and proceeded to the repair and testing stages of the trial. In total, 327 washing machines were successfully repaired, tested and re-labelled as re-use appliances. A total of 660 repairs and refurbishments were successfully carried out on these 327 appliances

\subsection{Quality}

In Figure 7, the graph shows the number of washing machines visually inspected from the delivered WEEE at the collection point vs. the number of machines subsequently selected for testing/preparation for reuse.

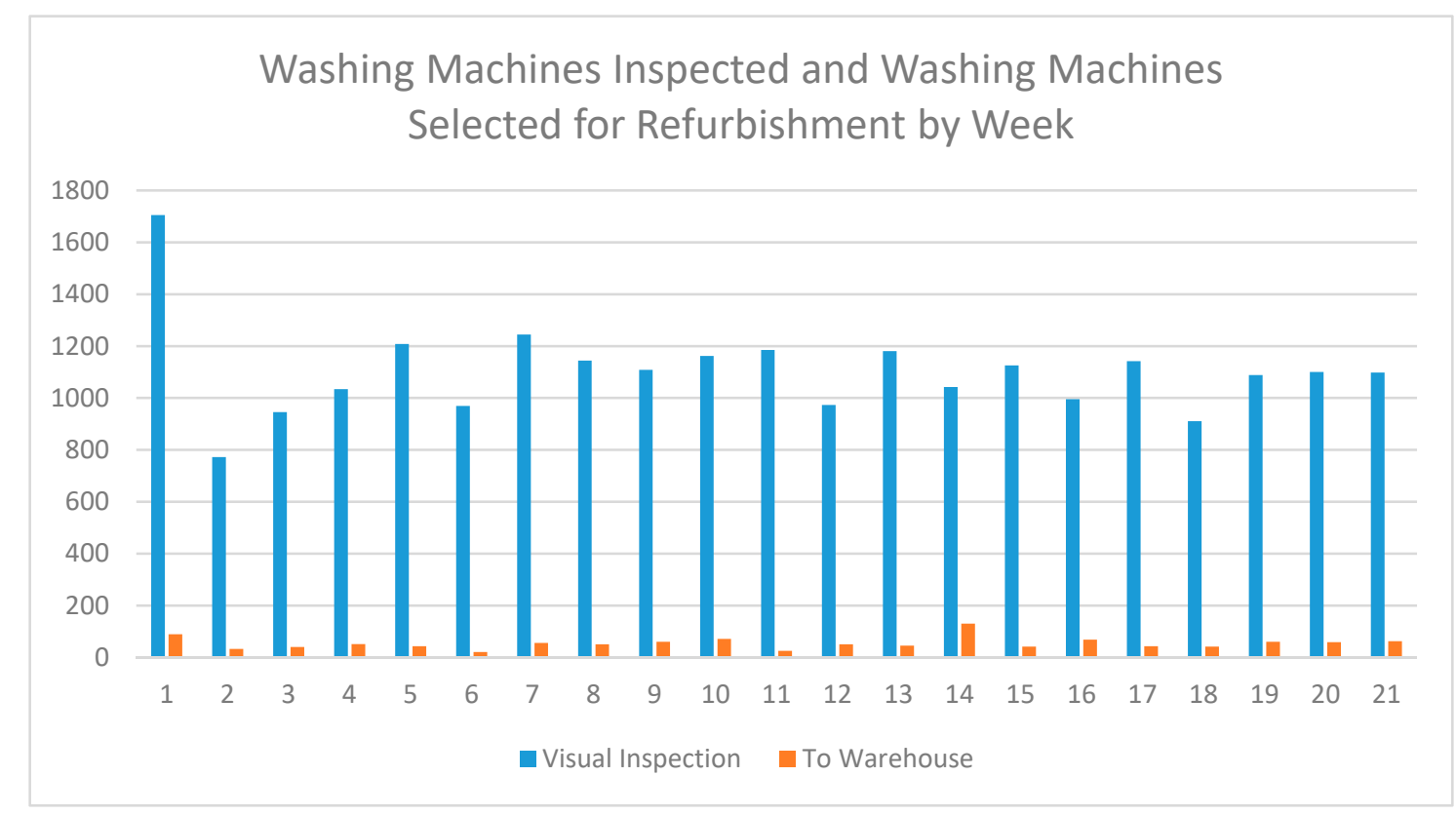

Figure 7. Ratio of appliances inspected vs. appliances selected for testing during the trial.

As shown in the chart, the percentage of recycle appliances selected at the pre-testing phase each week was approximately $5 \%$ across all of the weeks of the trial.

From the figure, it can be seen that only a small minority of washing machines which were received passed the first stage of visual inspection for preparation for re-use. The main reason for this was the poor condition of the LHA WEEE delivered to the collection point. Factors such as damage to the structural integrity of the appliance, the presence of (oftentimes significant) cosmetic dents, 
scratches and blemishes and general transportation damage to the appliances meant that, on average over the course of this study, only $4.91 \%$ of all LHA WEEE inspected began the refurbishment process.

This is a very significant detractor to any preparation for re-use undertaking of this magnitude, especially when it is considered that the pre-inspection phase is visual only and does not consider the functionality of the appliances in question. Studies such as that conducted by $[45,46]$ have found the situation to be similar in other EU countries. To maximise preparation for reuse potential, inspection and separation activities should take place as far upstream in the WEEE collection process as possible. This ensures that re-usable appliances are sent to adequate re-use channels without significant damage or blemish which could adversely impact their re-use potential. The findings of this trial serve as further evidence that separate/parallel collection points for preparation for re-use material(s) should exist as close to the initial WEEE collection point(s) as possible.

Figure 8 shows the number of appliances tested and the number of appliances which passed assessment and subsequently were repaired, tested and sold as re-used/refurbished washing machines by trial week. All of the appliances which passed the pre-inspection were then subjected to a thorough visual inspection and functional assessment, to determine if the washing machine was repairable, if cosmetic repairs or replacements were required and the associated costs for such refurbishment.

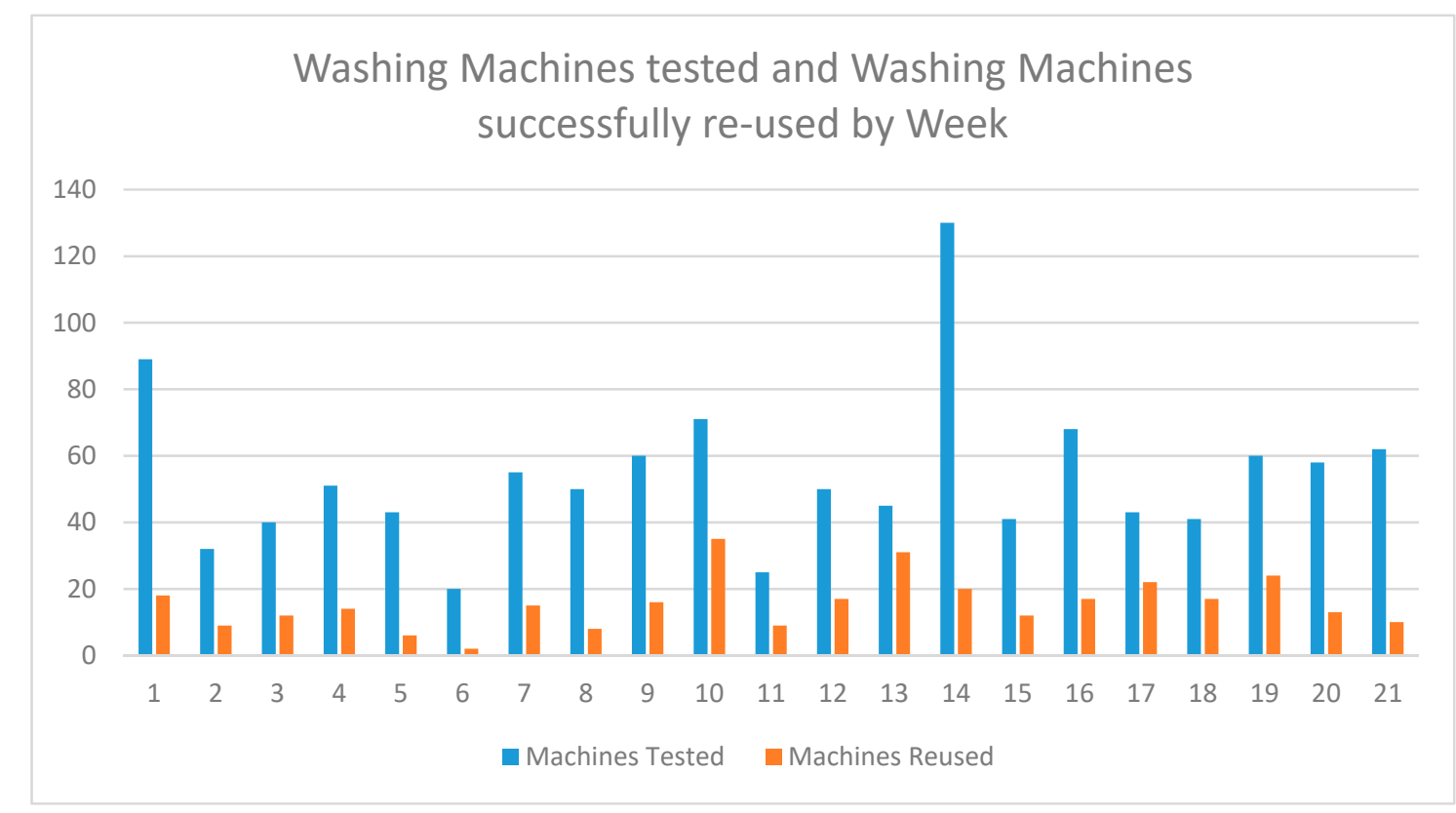

Figure 8. Appliances tested and appliances successfully re-used by trial week.

As calculated from this data, the average percentage of appliances which pass the functional assessment and visual inspection phase of the preparation for re-use process is $32.5 \%$. While this is a much better return on investment from a preparation for re-use viewpoint (representing one in three appliances re-used as opposed to the 19 in 20 appliances which fail the visual pre-inspection test), this still results in a cumulative repair rate of only $1.5 \%$ across all of the appliances inspected throughout the entire duration of the preparation for re-use trial.

\subsection{Causes of Failures}

Of the 327 washing machines which were successfully repaired, a total of 660 individual repairs and refurbishments were carried out, as described in Table 1. 
Table 1. Summary of all refurbishments completed during this preparation for re-use trial.

\begin{tabular}{cccc}
\hline Modification & Total & Modification & Total \\
\hline Brushes & 157 & Soap Box & 7 \\
New Motor & 114 & Cabinet & 3 \\
Door Seal & 82 & Pressure Switch & 3 \\
Mains Lead & 67 & Capacitor & 2 \\
Drain Pump & 47 & Drum Bearings & 2 \\
Door & 39 & Casing & 1 \\
PCB Board & 22 & Parts Fitted & 1 \\
Heating Element & 18 & Chamber & 1 \\
Front Panel & 18 & Wiring & 1 \\
Filter & 17 & Shocks & 1 \\
Panels & 13 & Drain & 1 \\
Outlet Hose & 12 & PC130 & 1 \\
Inlet Valves & 12 & Plint & 1 \\
Belt & 8 & Feet & 1 \\
Drum & 8 & & \\
\hline
\end{tabular}

The table shows the appliance repairs and refurbishments sorted in descending order. As can be seen from the data, the top six repairs carried out on all the washing machines during this preparation for re-use trial accounted for $77 \%$ of all the appliance repairs carried out. Specifically, the repairs in question were the replacement of motor brushes in existing washing machines, the installation of a new motor, replacement door(s) and/or door seals, installation of new mains leads and the installation of a new drain pump. In certain products, each of these repairs are relatively straightforward and easy to implement. If product design for these goods were modified to allow for easier access and replacement of these key components, the resulting appliances would be more easily repaired and maintained, resulting in better product lifetimes, re-use potential and overall refurbishment potential going forward.

The study also serves to highlight the range, scope and diversity of washing machine models currently on the market and being returned as WEEE in Ireland. Each of these washing machine models potentially had unique specifications and associated diagnostic requirements, meaning that the volume of required information necessary to successfully test, repair and re-use all of the models encountered was, in some cases, prohibitive. Furthermore, the lack of publicly available information on some of the washing machine brands/models further hampered repairs, testing and associated production yield in this regard.

Another factor adversely impacting the financial viability of the preparation for re-use trial was the availability and cost of OEM replacement parts for the washing machines repaired during the course of the study. OEM replacement parts for washing machines were not always readily available or easily sourced during this study, and where replacement parts were considered, the relatively high cost of these OEM replacement parts added a disproportionately large overhead to the running costs of the trails.

A third factor which had a negative impact on the preparation for re-use trial initially was the sourcing of suitably qualified and skilled repair personnel to affect the restoration, testing and refurbishment operations during the trial. Additional unskilled labour and associated overheads such as record-keeping, logging of data and asset management were also required for the duration of the trial, in addition to these skilled refurbishment personnel.

For LHA WEEE, another major cause of damage is the transport and storage of these units at collection and consolidation points. In particular, loading and unloading the units from transport and weather conditions such as rain etc. are key causes of damage which can result in appliances not being deemed suitable for preparation for re-use. Surface damage such as dents, marks and scratches resulting from transportation operations and functional failures resulting from the vulnerability of appliance electronics when exposed to inclement weather conditions are mainly at fault in this regard. Many 
collection containers at WEEE collection points lack sufficient roofing for the protection of goods that are potentially in good working order and would otherwise be appropriate for preparation for re-use activities. From a transportation viewpoint, the careless loading/unloading of WEEE into collection containers-independent of the prior condition of the appliance-and the subsequent damaging of either the device itself or other devices stored in the container are also concerns in this regard.

\section{Conclusions}

In this paper, the authors have presented a review and analysis of the potential for preparation for re-use of LHA/white goods appliances such as washing machines in Ireland. A methodology for the quantitative assessment of preparation for re-use potential of LHA WEEE is developed. This methodology is applied to a 21-week empirical study at a WEEE collection point.

In total, 23,129 appliances were inspected during the study, with 1134 machines or $4.9 \%$ of these selected for the trial after visual and functional assessment phases. From this, 327 washing machines were successfully refurbished, repaired and sold as reuse appliances giving an overall reuse rate of $1.5 \%$.

Within the causal analysis of the failure of these appliances for preparation for re-use, the causes are identified as functional failure during the use phase of the item or damages occurring during the WEEE collection phase of the item. For functional failures identified, key recommendations for addressing these include the use of modular and replaceable motors and drain pumps, modular and replaceable brushes, swappable power/mains leads and standardised doors and door seals across all makes and models of appliances. To address damages during collection, the appliances should be collected for re-use as far upstream in the WEEE collection process as possible. Changes to the mode of collection, transport and storage conditions used for WEEE would yield a much higher percentage of equipment which is suitable for re-use.

Author Contributions: Conceptualization, C.F. and M.J.; Methodology, M.J. and K.M..; Software, M.J.; Validation, M.J., K.M. and C.F.; Formal Analysis, C.F.; Investigation, M.J.; Resources, K.M.; Data Curation, M.J.; Writing_-original draft preparation, M.J.; writing-review and editing, C.F. and K.M..; visualization, M.J.; supervision, M.J.; project administration, M.J.; funding acquisition, C.F. All authors have read and agreed to the published version of the manuscript.

Funding: This research was funded by the Environmental Protection Agency, Ireland under Research 241: Research of Upcycling Supports to Increase Re-use, with a Focus on Waste Electrical and Electronic Equipment (UpWEEE).

Acknowledgments: The authors would also like to thank Stewart Hickey for his assistance and support in this project.

Conflicts of Interest: The authors declare no conflict of interest.

\section{References}

1. Kissling, R.; Fitzpatrick, C.; Boeni, H.; Luepschen, C.; Andrew, S.; Dickenson, J. Definition of generic re-use operating models for electrical and electronic equipment. Resour. Conserv. Recycl. 2012, 65, 85-99. [CrossRef]

2. González, X.M.; Rodríguez, M.; Pena-Boquete, Y. The social benefits of WEEE re-use schemes. A cost benefit analysis for PCs in Spain. Waste Manag. 2017, 64, 202-213. [CrossRef] [PubMed]

3. Lindkvist, L.; Movilla, N.A.; Sundin, E.; Zwolinski, P. Investigating types of information from WEEE take-back systems in order to promote Design for Recovery. In Sustainability through Innovation in Product Life Cycle Design; Springer: Singapore, 2017; pp. 3-19.

4. Lu, B.; Yang, J.; Ijomah, W.; Wu, W.; Zlamparet, G. Perspectives on reuse of WEEE in China: Lessons from the EU. Resour. Conserv. Recycl. 2018, 135, 83-92. [CrossRef]

5. Directive (EU) of the European Parliament and of the Council of 30 May 2018 Amending Directive 2008/98/EC on Waste. Available online: https://eur-lex.europa.eu/legal-content/EN/TXT/PDF/?uri=CELEX: 32018L0851\&from =EN (accessed on 9 October 2019).

6. The Flemish Reuse Network-The Importance of Reuse Targets. Available online: http://www.rreuse.org/ wp-content/uploads/Komosie-Flanders.pdf (accessed on 9 October 2019).

7. Eco-systèmes et la Filière DEEE en France. Available online: http://www.rreuse.org/wp-content/uploads/ Eco-systemes.pdf (accessed on 9 October 2019). 
8. Resource Opportunity. Available online: https:/www.epa.ie/pubs/reports/waste/plans/Resource_ Opportunity2012.pdf (accessed on 9 October 2019).

9. S.I. No. 126 of 2011. Available online: http://www.irishstatutebook.ie/eli/2011/si/126/made/en/pdf (accessed on 9 October 2019).

10. S.I. No. 323 of 2011. 323 of 2011. Available online: http://www.irishstatutebook.ie/eli/2011/si/323/made/en/pdf (accessed on 9 October 2019).

11. Questionnaire on Implementation of Directive 2008/98/EC, C 2384 Final. Available online: https://ec.europa. eu/environment/archives/waste/reporting/pdf/C_2012_2384.pdf (accessed on 9 October 2019).

12. Truttmann, N.; Rechberger, H. Contribution to resource conservation by reuse of electrical and electronic household appliances. Resour. Conserv. Recycl. 2006, 48, 249-262. [CrossRef]

13. McMahon, K.; Fitzpatrick, C.; Johnson, M. Enabling preparation for re-use of waste electrical and electronic equipment in Ireland: Lessons from the EU. J. Clean. Prod. 2019, 232, 1005-1017. [CrossRef]

14. Kahhat, R.; Kim, J.; Xu, M.; Allenby, B.; Williams, E.; Zhang, P. Exploring e-waste management systems in the United States. Resour. Conserv. Recycl. 2008, 52, 955-964. [CrossRef]

15. Phillips, P.S.; Tudor, T.; Bird, H.; Bates, M. A critical review of a key waste strategy initiative in England: Zero waste places projects 2008-2009. Resour. Conserv. Recycl. 2011, 55, 335-343. [CrossRef]

16. Zhijun, F.; Nailing, Y. Putting a circular economy into practice in China. Sustain. Sci. 2007, 2, 95-101. [CrossRef]

17. Directive, E.U. 96/EC of the European Parliament and of the Council of 27 January 2003 on waste electrical and electronic equipment (WEEE). Off. J. Eur. Union L 2002, 37, 24-38.

18. Bertoldi, P.; Atanasiu, B. Electricity Consumption and Efficiency Trends in the Enlarged European Union; Institute for Environment and Sustainability: Ispra, VA, Italy, 2007.

19. Kallis, G.; Butler, D. The EU water framework directive: Measures and implications. Water Policy 2001, 3, 125-142. [CrossRef]

20. Lin, C.K.; Yan, L.; Davis, A.N. Globalization, extended producer responsibility and the problem of discarded computers in China: An exploratory proposal for environmental protection. Geo. Int'l Envtl. L. Rev. 2001, 14, 525.

21. Kang, H.Y.; Schoenung, J.M. Electronic waste recycling: A review of US infrastructure and technology options. Resour. Conserv. Recycl. 2005, 45, 368-400. [CrossRef]

22. Ongondo, F.O.; Williams, I.D.; Cherrett, T.J. How are WEEE doing? A global review of the management of electrical and electronic wastes. Waste Manag. 2011, 31, 714-730. [CrossRef] [PubMed]

23. Seyring, N.; Kling, M.; Weissenbacher, J.; Hestin, M.; Lecerf, L.; Magalini, F.; Khetriwal, D.S.; Kuehr, R. Study on WEEE Recovery Targets, Preparation for Re-Use Targets and on the Method for Calculation of the Recovery Targets; EU Commission: Brussels, Belgium, 2015.

24. Sander, K.; Schilling, S.; Tojo, N.; van Rossem, C.; Vernon, J.; George, C. The Producer Responsibility Principle of the WEEE Directive; Ökopol GmbH: Hammburg, Germany, 2007.

25. Messmann, L.; Boldoczki, S.; Thorenz, A.; Tuma, A. Potentials of preparation for reuse: A case study at collection points in the German state of Bavaria. J. Clean. Prod. 2019, 211, 1534-1546. [CrossRef]

26. O'Connell, M.W.; Hickey, S.W.; Fitzpatrick, C. Evaluating the sustainability potential of a white goods refurbishment program. Sustain. Sci. 2013, 8, 529-541.

27. Pérez-Belis, V.; Bovea, M.D.; Ibáñez-Forés, V. An in-depth literature review of the waste electrical and electronic equipment context: Trends and evolution. Waste Manag. Res. 2015, 33, 3-29. [CrossRef]

28. Queiruga, D.; Queiruga-Dios, A. The Reuse of Waste Electrical and Electronic Equipment (WEEE). A Bibliometric Analysis. Int. J. Waste Resour. 2015, 5, 1-8.

29. Beasley, J.; Georgeson, R. Reuse in the UK and Ireland-A State of the Nations Report for the Chartered Institution of Wastes Management. Available online: https:/www.ciwm.co.uk/Custom/ BSIDocumentSelector/Pages/DocumentViewer.aspx?id=QoR7FzWBtisamYEcWSfL6SxAJRLAPT9vBc\% 252bTYqJHvnk4x6Vs7OvblCqRbvdFeQO815NlcYg2tcAXWIngFm8ZnZdcmRrxViHOPh\% 252fy6VW9Zy0Cy1AJ708iABJPjQg\%252bFJx5xfECiCkK0AMZjqmupb2Vrh8wqpHNbXf2 (accessed on 21 October 2019).

30. Cole, C.; Gnanapragasam, A.; Cooper, T.; Singh, J. Assessing barriers to reuse of electrical and electronic equipment, a UK perspective. Resour. Conserv. Recycl. 2019, 1, 100004. [CrossRef] 
31. Löhle, I.S.; Bartnik, S.; Ehrenbrink, M.; Müller, M. Förderung der Vorbereitung zur Wiederverwendung von Elektro (nik) Altgeräten; Cyclos GmbH: Hamburg, Germany, 2016.

32. Neitsch, M.; Spitzbart, M.; Hammerl, B.; Schleich, B. Umsetzungskonzept zur Implementierung des Gebotes der Wiederverwendung-Gemäß ARL2008 in Österreich. Available online: http://www.repanet.at/re-use-toolbox/re-use-repathek/umsetzungskonzept-zur-implementierungdes-gebotes-der-wiederverwendung-gemaess-arl2008-in-oesterreich (accessed on 21 October 2019).

33. Spitzbart, M.; Thaler, A.; Stachura, M. Leitfaden für die Wiederverwendung von Elektroaltgeräten in Österreich: Ergebnis der ReUse-Plattform. Available online: http://www.kerp.at/uploads/media/KERP_-_ ReuseLeitfaden.pdf (accessed on 21 October 2019).

34. Johnson, M.; McMahon, K.; Fitzpatrick, C. Research of Upcycling Supports to Increase Re-Use, with a Focus on Waste Electrical and Electronic Equipment. Available online: http://www.epa.ie/researchandeducation/ research/researchpublications/researchreports/research241.html (accessed on 21 October 2019).

35. WRAP, Composition of Kerbside and HWRC Bulky Waste. 2012. Available online: http://www.wrap.org.uk/ content/bulky-waste-technical-report (accessed on 21 October 2019).

36. Curran, A.; Williams, I.D.; Heaven, S. Management of household bulky waste in England. Resour. Conserv. Recycl. 2007, 51, 78-92. [CrossRef]

37. Parajuly, K.; Wenzel, H. Potential for circular economy in household WEEE management. J. Clean. Prod. 2017, 151, 272-285. [CrossRef]

38. Bovea, M.D.; Ibáñez-Forés, V.; Pérez-Belis, V.; Quemades-Beltrán, P. Potential reuse of small household waste electrical and electronic equipment: Methodology and case study. Waste Manag. 2016, 53, $204-217$. [CrossRef] [PubMed]

39. Dwivedy, M.; Suchde, P.; Mittal, R.K. Modeling and assessment of e-waste take-back strategies in India. Resour. Conserv. Recycl. 2015, 96, 11-18. [CrossRef]

40. Estrada-Ayub, J.A.; Kahhat, R. Decision factors for e-waste in Northern Mexico: To waste or trade. Resour. Conserv. Recycl. 2014, 86, 93-106. [CrossRef]

41. Kilic, H.S.; Cebeci, U.; Ayhan, M.B. Reverse logistics system design for the waste of electrical and electronic equipment (WEEE) in Turkey. Resour. Conserv. Recycl. 2015, 95, 120-132. [CrossRef]

42. Özkır, V.Ç.; Efendigil, T.; Demirel, T.; Demirel, N.C.; Deveci, M.; Topçu, B. A three-stage methodology for initiating an effective management system for electronic waste in Turkey. Resour. Conserv. Recycl. 2015, 96, 61-70. [CrossRef]

43. Manomaivibool, P.; Hong, J.H. Two decades, three WEEE systems: How far did EPR evolve in Korea's resource circulation policy? Resour. Conserv. Recycl. 2014, 83, 202-212. [CrossRef]

44. Hertwich, E.G.; Ali, S.; Ciacci, L.; Fishman, T.; Heeren, N.; Masanet, E.; Asghari, F.N.; Olivetti, E.; Pauliuk, S.; $\mathrm{Tu}, \mathrm{Q}$.; et al. Material efficiency strategies to reducing greenhouse gas emissions associated with buildings, vehicles, and electronics-A review. Environ. Res. Lett. 2019, 14, 043004. [CrossRef]

45. Ylä-Mella, J.; Poikela, K.; Lehtinen, U.; Keiski, R.L.; Pongrácz, E. Implementation of waste electrical and electronic equipment directive in Finland: evaluation of the collection network and challenges of the effective WEEE management. Resour. Conserv. Recycl. 2014, 86, 38-46. [CrossRef]

46. Zheng, J.L.; Zheng, C.; Chen, P.; Luk, C.Y. An Evaluation Model for the Coordinated Development of a Circular Economy in China and Its Application to Energy-intensive Industries. Front. Eng. Manag. 2015, 1, 364-371. [CrossRef]

(C) 2020 by the authors. Licensee MDPI, Basel, Switzerland. This article is an open access article distributed under the terms and conditions of the Creative Commons Attribution (CC BY) license (http://creativecommons.org/licenses/by/4.0/). 